\title{
Hydrogels by irradiation of a synthetic heparinoid polyelectrolyte
}

\author{
L.C. Sederel, L. van der Does, B.J. Euverman, and A. Bantjes \\ Department of Chemical Technology, Biomaterials section, Twente University of Technology, P.O. Box 217, \\ Enschede, The Netherlands
}

\author{
C. Kluft and H.J.M. Kempen \\ Gaubius Institute TNO, Leiden, The Netherlands. \\ (Received 1 March 1982; revised 8 April 1982)
}

\begin{abstract}
Gamma irradiation of aqueous solutions of a synthetic heparinoid polyelectrolyte results in the formation of hydrogels, varying in water content and mechanical strength. The equilibrium water content and the mechanical strength of the hydrogels are dependent on the initial polyelectrolyte concentration, the molecular weight of the polyelectrolyte, the percentage of double bonds in the polyelectrolyte and the radiation dose.

The polyelectrolyte hydrogels do not deplete Antithrombin III from blood and there is no activation of factor XII according to an in vitro kallikrein generation test. However, in a very sensitive test for factor XII activation (contact promoted shortening of the thrombotest) a slight activation of this factor was observed.
\end{abstract}

Keywords: Polymer, hydrogel, heparin polyelectrolyte, antithrombin III, irradiation

In this paper data will be given about the synthesis and the biological activity of polyelectrolyte hydrogels, prepared by irradiation of aqueous polyelectrolyte solutions.

A hydrogel is defined as a slightly or moderately crosslinked polymer, which has the ability to swell but not to dissolve and retain a significant fraction of water in its structurc ${ }^{1}$. Various types of hydrogels have been developed for biomedical applications. Among these synthetic hydrogels, poly(hydroxyethyl methacrylate $)^{2-5}$, polyacrylamide $^{5-7}$ and polyvinyl alcohol ${ }^{8-11}$ are most widely used for the good biocompatibility, and high water permeability, the characteristics desirable for enzyme support and for the controlled release of drugs, exhibited by the gels. Many of these hydrogels have also shown promise for cardiovascular applications ${ }^{15}$.

The relationship between the equilibrium water content of these gels and their interaction with blood has been the subject of much speculation and of extended investigation. The equilibrium water content of the gels depends on several parameters, among which are the crosslink density and the nature and number of the hydrophilic sites in the macromolecular matrix ${ }^{12}$.

In a number of studies platelets were found to be relatively non-adhesive to hydrogels ${ }^{3-15}$, and using the vena cava ring test results were obtained varying from fair to outstanding ${ }^{16-18}$. However, the renal embolus test indicated that hydrogels are generally thromboembolic ${ }^{15,19}$.

The majority of the hydrogels are prepared by the radiation technique ${ }^{20-23}$. The formation of crosslinked gels under irradiation was first studied in the case of water-soluble polymers by Alexander and Charlesby ${ }^{22}$. The use of radiation has certain advantages, like the lack of heat treatment, and absence of additives and catalysts. A review of the applications of ionizing radiation processing for the preparation of biomaterials is given by Hoffman ${ }^{21}$.
The result of irradiation can be, that side chains or hydrogen atoms are split off from the polymer (direct action). The radicals formed on adjacent chains can combine to give a covalent bond, thereby linking the polymer molecules ${ }^{20,23}$. A point is soon reached at which an incipient closed network is formed (gel) and this completely transforms the physical properties of the material. Degradation may also occur and contrary to the radiation-induced crosslinking, polymer degradation takes place by scission of bonds in the main chain. The radiation-induced crosslinking or degradation, appears to depend on the chemical structure of the polymers, but although a large number of polymers show both effects, usually one or the other predominates.

When aqueous solutions of polymers are irradiated the energy is also captured by the water molecules causing chemical changes. The products formed are: $\mathrm{e}^{-}$aq, $\mathrm{OH}^{\circ}, \mathrm{H}^{\cdot}, \mathrm{H}_{2}, \mathrm{H}_{2} \mathrm{O}_{2}$ and $\mathrm{H}_{3} \mathrm{O}^{+24}$. These products can also react with and modify the polymer molecules (indirect action), resulting in a crosslinked network.

In previous publications we reported the preparation of a water-soluble polyelectrolyte, derived from cis-1,4-polyisoprene, having anticoagulant activity ${ }^{25-31}$. This polyelectrolyte consists of the following structural units:<smiles>CCC=C(C)CC</smiles><smiles>CCC(C(=O)[O-])C(C)(CC)NS(=O)(=O)[O-]</smiles><smiles>CC=C(C)C(CC)C(N)=O</smiles>

(C) 1983 Butterworth \& Co (Publishers) Ltd. 0142-9612/83/040003-06 $\$ 03.00$ 
The polyelectrolyte resembles heparin in many respects ${ }^{26,30,31}$. Like heparin the polymer can be linked ionically to polymer surfaces by means of an adsorptive coupling agent, e.g. tridodecylmethylammonium chloride (TDMAC) ${ }^{32,33}$. Polymer surfaces, coated with the TDMA-polyelectrolyte complex showed reduced platelet adhesion, when exposed to freshly drawn human blood $^{34}$. However, like the TDMA-heparin coatings ${ }^{35}$, these coatings were not stable in plasma and phosphate buffered saline and loss of polyelectrolyte from the surface occurred ${ }^{30}$.

Using gamma-irradiation it was possible to attach low molecular weight polyelectrolyte covalently onto silicone rubber $^{36}$ and to crosslink high molecular weight polyelectrolyte on the surface and in the pores of a polystyrene resin ${ }^{36,37}$. In vitro experiments with human and canine blood showed that the coated surfaces showed less platelet adhesion than the uncoated ones.

In consequence the effect of irradiation of aqueous solutions of the polyelectrolyte was also studied. It was observed that crosslinking had occurred by irradiation resulting in the formation of hydrogels. These hydrogels may have some very interesting properties because they consist of a cross-linked anticoagulant and water.

\section{EXPERIMENTAL}

\section{Hydrogel preparation}

The polyelectrolytes (PLE-A, PLE-B and PLE-C) were prepared according to a method described before $^{25-28,31}$. The starting material was cis-1,4-polyisoprene (Cariflex 307, Shell, $\bar{M}_{n}=270000, \bar{M}_{w} / \bar{M}_{n}=5.3$ ).

In a nitrogen atmosphere a solution of cis-1,4polyisoprene in toluene was added, at room temperature, to a stirred solution of chlorosulphonyl isocyanate (CSI) in toluene [molar ratio CSI: isoprene $=3: 1$ (PLEA), 1.5:1 (PLE-B) and 1:1 (PLE-C)]. Polyelectrolytes were synthesized from the CSI adducts by hydrolysis with a sodium hydroxide solution at $100^{\circ} \mathrm{C}$. The polyelectrolytes were purified by dialysis against distilled water for three days, followed by freeze-drying of the solutions.

Glass tubes, filled with polyelectrolyte solutions were irradiated with ${ }^{60} \mathrm{Co}$ gamma radiation, at a dose rate of approximately $0.2 \mathrm{Mrad} / \mathrm{h}$ (Interuniversity Reactor Institute, Delft or Gammaster, Ede). In some cases a crosslinking agent $\mathrm{N}, \mathrm{N}^{\prime}$-methylene bisacrylamide, was added to the polyelectrolyte solution. Unless otherwise indicated, solutions were not degassed.

After irradiation the hydrogels were treated with $0.16 \mathrm{M}$ sodium chloride until equilibrium swelling was attained at room temperature for $24 \mathrm{~h}(25 \mathrm{ml}$ of sodium chloride solution $2 \mathrm{~g}$ hydrogel).

\section{Methods of characterization}

Elemental analyses were performed by the Organic Chemical Institute, TNO, Utrecht. The absolute error in the weight percentages of the elements was $0.2 \%$.

Possible leakage of polyelectrolyte from the hydrogels was measured spectrophotometrically with the aid of the cationic dye Azur $A^{36,38}$ at a wavelength of $620 \mathrm{~nm} .5 \mathrm{ml}$ of Azur A solution ( $c=8 \mathrm{mg} / \mathrm{ml}, \mathrm{pH}=7.5$ ) was added to $0.5 \mathrm{ml}$ of sample. Azur A forms a purple coloured complex with the polyelectrolyte, which partly precipitates from the solution. After removal of the precipitate by centrifugation the extinction was measured and a calibration curve constructed.

The mechanical strength of the swollen gels was measured with a modification of a Durometer (ASTM designation D 2240-64 T) and a Penetrometer (ASTM

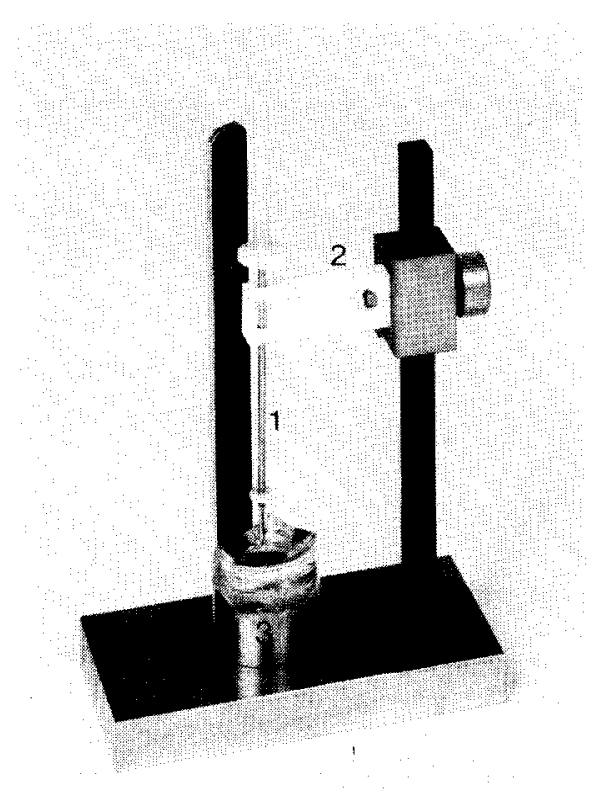

Figure 1 Apparatus for the determination of the mechanical strength of the hydrogels. (1) needle and plunger; (2) teflon holder; (3) test specimen container.

designation $D$ 1321) (Figure 1). In the tests a needle with a sharp point, $10 \mathrm{~mm}$ long $\times 1 \mathrm{~mm}$ diameter was connected to the end of a $50 \mathrm{~mm}$ long plunger. The total weight of plunger and needle was $1.0 \mathrm{~g}$. The plunger can fall through the teflon holder without appreciable friction. The penetration of the needle in the hydrogel was followed with the aid of a cathetometer. The weight, necessary for complete penetration of the needle in the gel, within $30 \mathrm{~s}$ was measured by increasing the weight of the plunger in steps of $0.5 \mathrm{~g}$. For biological activity measurements the gels were crushed by pressing through a syringe with an outstream diameter of $1 \mathrm{~mm}$. The kallikrein-generation test and the thrombotest were carried out with gel suspensions (crushed gels four times diluted with $0.16 \mathrm{M} \mathrm{NaCl}$ ).

The adsorption of Antithrombin III (AT III) by the gels was studied with the Rocket immuno electrophoresis technique of Laure $\|^{39}$. To $1 \mathrm{ml}$ of crushed gel $2 \mathrm{ml}$ of citrated human blood was added. After incubation during $1 \mathrm{~h}$ at $37^{\circ} \mathrm{C}$ the mixture was centrifuged. The AT III content of the supernatant plasma was determined. Blank experiments were carried out with $0.16 \mathrm{M} \mathrm{NaCl}$ instead of the crushed gels.

The kallikrein-generation test ${ }^{40,41}$ and the contact promoted shortening of the thrombotest (CPS thrombotest ${ }^{42}$ were used to explore the ability of the gels to activate factor XII.

The kallikrein-generation test. $100 \mu$ of citrated human plasma and $100 \mu \mathrm{l}$ of gel suspension were mixed and incubated for $15 \mathrm{~min}$ at $0^{\circ} \mathrm{C}$. After the incubation time the mixture was centrifuged and from an aliquot of the supernatant the activity of the generated kallikrein was measured on the kallikrein specific synthetic substrate $\alpha-N$-benzoyl-L-proline-L-phenylalanine-L-arginine-p-nitroaniline (PPAN).

$3 \mu \mathrm{l}$ of the supernatant was added to $200 \mu$ l buffer (0.1\% Carbowax, $0.1 \%$ polybrene, $\mathrm{pH}=7.9, \mathrm{I}=0.15$ $\left.T=37^{\circ} \mathrm{C}\right)$, to which $40 \mu$ l of PPAN solution $(1 \mathrm{mM})$ had been added just before. After mixing, the absorption of p-nitroaniline was measured with a Unicam SP 1800 UV spectrophotometer, at a wavelength of $405 \mathrm{~nm}$. The generated activity was compared with the activity of the 
blank $(0.16 \mathrm{M} \mathrm{NaCl})$ and the one generated spontaneously with a solution of dextran sulphate $\left(\bar{M}_{n}=500,000,25 \mu \mathrm{g} / \mathrm{ml}\right)$. The latter causes a $100 \%$ conversion of prekallikrein into kallikrein. In cases where no kallikrein generation was observed, $100 u$ of the dextran sulphate solution was added to the plasma/gel mixture, as a control for the possible adsorption of factor XII and/or (pre)kallikrein by the hydrogels.

The CPS-thrombotest. $200 \mu$ of citrated human plasma was incubated during $24 \mathrm{~h}$ with $200 \mu \mathrm{l}$ of gel suspension at $0^{\circ} \mathrm{C}$. As a control the experiments were also carried out with $0.16 \mathrm{M} \mathrm{NaCl}$ and with a dextran sulphate solution $(3.3 \mu \mathrm{g} / \mathrm{ml})$. After the contact time the mixture was centrifuged and clotting times were measured with a clot-timer (Schnitger and Gross): to $100 \mu \mathrm{l}$ of supernatant $\left(37^{\circ} \mathrm{C}\right) 200 \mu \mathrm{l}$ of thrombotest (TT) reagent $\left(T=37^{\circ} \mathrm{C}\right)$ (Nyegaard, Oslo, Norway) was added.

\section{RESULTS AND DISCUSSION}

\section{Hydrogel formation}

Irradiation of polyelectrolyte solutions resulted in the formation of hydrogels, the properties of which were markedly dependant on the composition of the initial polyelectrolytes.

Table 1 shows elemental analyses of the starting polyelectrolytes and of H-PLE-A after $\gamma$-irradiation. From these data it can be calculated that irradiation of a solution of polyelectrolyte PLE-A with $15 \mathrm{Mrads}$ resulted in an increase of the $\mathrm{C} / \mathrm{N}$ ratio of $6 \%$ and of the N/S ratio of $3 \%$, respectively.

Elemental analyses of a large number of polyelectrolytes, derived from cis-1,4-polyisoprene, indicated that they are composed of unreacted isoprene units $\left(\mathrm{C}_{5} \mathrm{H}_{8}\right)$, water and the following structural units:<smiles>CCC(C(=O)[O-])C(C)(CC)NS(=O)(=O)[O-]</smiles><smiles>CC=C(C)C(CC)C(N)=O</smiles>

$$
\left(\mathrm{C}_{6} \mathrm{H}_{9} \mathrm{NSO}_{5} \mathrm{Na}_{2}\right)
$$

$$
\left(\mathrm{C}_{6} \mathrm{H}_{9} \mathrm{NO}\right)
$$

In Table 2 the calculated compositions of the polyelectrolytes PLE-A, PLE-B and PLE-C are shown.

The decrease of the molar ratio of chlorosulphonyl isocyanate to isoprene units from 3.0 to 1.0 showed that polyelectrolytes had been formed with higher percentages of double bonds and lower percentages of structural units $b$, going from PLE-A to PLE-C. It is probable, that the decrease of the CSI/isoprene molar ratio had resulted in the formation of polyelectrolytes

Table 1 Elemental analyses of the polyelectrolytes

\begin{tabular}{rrrrr}
\hline & PLE-A & PLE-B & PLE-C & H-PLE-A $^{1}$ \\
\hline C & 33.33 & 43.62 & 45.17 & 35.99 \\
H & 5.86 & 7.06 & 6.69 & 5.35 \\
N & 4.71 & 4.32 & 3.95 & 4.79 \\
S & 9.19 & 6.73 & 4.90 & 9.14 \\
\hline
\end{tabular}

1 H-PLE-A; a solution of PLE-A in water $(C=10 \mathrm{~g} / 100 \mathrm{ml})$ was irradiated with 15 Mrads, followed by freeze-drying of the gel.
Table 2 Calculated composition of polyelectrolytes ( $\mathrm{mol}$ fractions)

PLE $\quad \mathrm{C}_{5} \mathrm{H}_{8} \quad \mathrm{C}_{6} \mathrm{H}_{9} \mathrm{NSO}_{5} \mathrm{Na}_{2} \quad \mathrm{C}_{6} \mathrm{H}_{9} \mathrm{NO}^{\mathrm{H}} \quad \mathrm{H}_{2} \mathrm{O}$ molar ratio $\mathrm{c} / \mathrm{b}$

(a) (b) $\quad$ (c) $\quad$ (d) ${ }^{*}$ CSI/isoprene

$\begin{array}{lllllll}\text { PLE-A } & 0.31 & 0.59 & 0.10 & 1.66 & 3.0 & 0.17\end{array}$

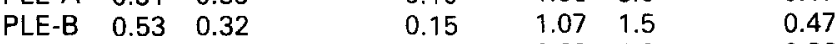

$\begin{array}{lllllll}\text { PLE-C } & 0.59 & 0.22 & 0.19 & 0.60 & 1.0 & 0.86\end{array}$

* mol/mol polyelectrolyte

with a higher molecular weight, since less chain scission will occur, when a lower excess of CSI is present in the reaction mixture ${ }^{29}$. The variation in chemical composition and in molecular weight of the polyelectrolytes had an effect on the solubility in water: Solutions with a concentration of $10 \mathrm{~g} / 100 \mathrm{ml}$ were slightly viscous (PLEA), viscous (PLE-B) or were gels (PLE-C).

Upon irradiation of the polyelectrolyte solutions, gas bubbles were formed and also with the freezethawing procedure of Peppas and Merrill ${ }^{10}$ the formation of gas bubbles (probably hydrogen formation) could not be avoided.

Solutions of PLE-A were irradiated with $3.5,10$ and $15 \mathrm{Mrads}$ and the initial polyelectrolyte concentrations were 5, 10 and $20 \mathrm{~g} / 100 \mathrm{ml}$, respectively. In Figure 2 the relation between the initial polyelectrolyte concentration ([PLE $]_{0}$ ) and the equilibrium water content of the irradiated polyelectrolytes is shown, after swelling in $0.16 \mathrm{M} \mathrm{NaCl}$

To some of the polyelectrolyte solutions $N, N^{\prime}$ methylene bisacrylamide was added as a crosslinking agent (molar ratios of crosslinker/double bonds in the polyelectrolytes were $0.01,0.02$ and 0.1 , respectively). Since the presence of a crosslinker seemed to have only a slight influence on the equilibrium water content of the hydrogels (see curves 1-4 (15 Mrads) in Figure 2), for 3.5 and 10 Mrads only one (mean) curve is given, representing experiments with different concentrations of crosslinker. From the graphs in Figure 2 it can be concluded that the equilibrium water content of the hydrogels decreases by using higher radiation dose and higher initial concentration of the polyelectrolyte. The dependance on radiation dose seems to be most pronounced at higher concentrations.

In order to obtain more information about the effect of the initial concentration on the equilibrium water content of the hydrogels, more concentrated

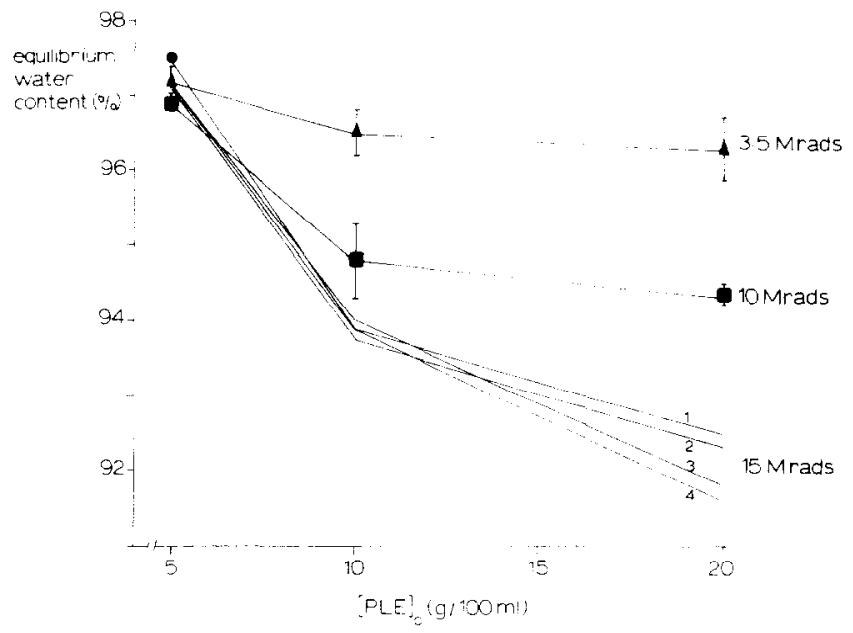

Figure 2 Equilibrium water content of swollen hydrogels $H$ PLE-A versus initial polyelectrolyte concentration. Molar ratio crosslinker*/double bonds in the polyelectrolyte: 0.00 (1), 0.01 (4), 0.02 (3) and 0.7 (2). Bars indicate standard deviation.

* N,N'-methylene bisacrylamide. 


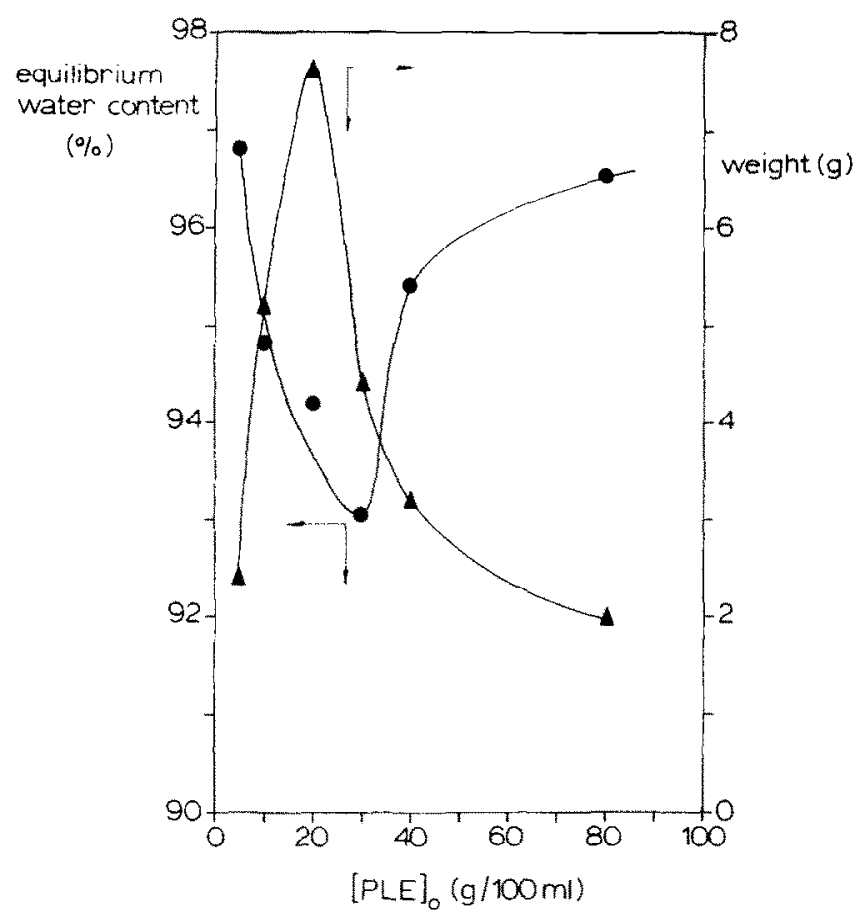

Figure 3 Equilibrium water content and mechanical strength of hydrogels H.PLE-A versus initial polyelectrolyte concentration. Radiation dose 10 Mrads.

solutions had to be studied. However, the maximum concentration in which PLE-A can be dissolved in wate is $20 \mathrm{~g} / 100 \mathrm{ml}$. In order to decrease the water content of the polyelectrolyte solutions, water was evaporated from the solutions in a vacuum desiccator. In Figure 3 the initial polyelectrolyte concentration, the equilibrium water content and data about the mechanical strength of the hydrogels are shown.

The weight of a plunger in grams, necessary for the complete penetration of a needle in the hydrogel within $30 \mathrm{~s}$, was used as a measure of the mechanical strength of the hydrogels. The low mechanical strength of the hydrogels prevented use of the Durometer (ASTM designation D 2240-64T) and the Penetrometer (ASTM D 1321). The presence of gas bubbles in the hydrogels also prevented the latter, therefore a lighter plunger and a shorter needle were used in our apparatus.

It can be concluded from the data in Figure 3 that decreasing the equilibrium water content of the hydrogels, generally leads to stronger gels, as was expected. A maximum in the mechanical strength was found at an initial polyelectrolyte concentration of $20 \mathrm{~g} / 100 \mathrm{ml}$. A further increase of the initial concentration resulted, after irradiation with 10 Mrads, in hydrogels with lower mechanical strength. This result can be explained by a decrease in the indirect action in more concentrated polyelectrolyte solutions. In the solvent (water) less hydroxyl radicals are formed to contribute to the crosslinking of the polymeric chains. Similar observations have been reported by Peppas ${ }^{8}$, who found that diluted polyvinyl alcohol solutions lead to more densely crosslinked materials than concentrated ones, using the same radiation dose. Also the high viscosity of the more concentrated polyelectrolyte solutions might have a negative influence on the crosslinking, because of the lower mobility of the radicals and polymeric chains.

With the aim to increase the strength of the hydrogels, solutions of polyelectrolytes with a higher

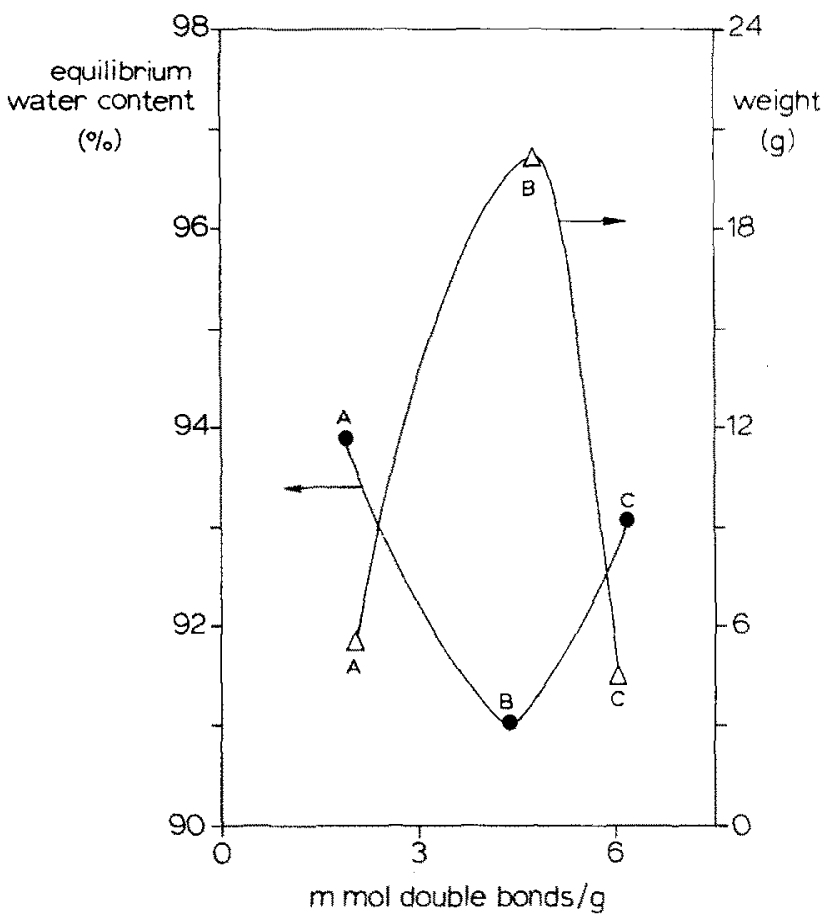

Figure 4 Equilibrium water content and mechanical strength of hydrogels H-PLE-A, H-PLE-B and H-PLE-C versus the amount of double bonds in the polyelectrolytes. $[P L E-X]_{0}=10 \mathrm{~g} /$ $100 \mathrm{ml}$, radiation dose 15 Mrads. Initial polyelectrolyte solution: PLE-A : sl. viscous, PLE-B: viscous, PLE-C: gel.

percentage of double bonds were irradiated (PLE-B and PLE-C). Aqueous solutions of PLE-B, PLE-C, and in addition PLE-A for comparison, with a concentration of $10 \mathrm{~g} / 100 \mathrm{ml}$, were irradiated with a total dose of 15 Mrads. From the hydrogels the equilibrium water content and the mechanical strength were determined (Figure 4).

Irradiation of a solution of PLE-B with 15 Mrads resulted in the formation of a hydrogel with a lower water content and a higher mechanical strength, than a hydrogel prepared from PLE-A under the same reaction conditions. Because there is a higher percentage of double bonds in PLE-B, the polyelectrolyte will be more sensitive to the indirect radiation action, resulting in a more crosslinked network. A further increase in unsaturation (PLE-C) resulted in a hydrogel with a higher equilibrium water content and a lower mechanical strength. This can be explained as due to the high viscosity of the initial solution, leading to a low mobility of the radicals and polymeric chains.

\section{Release experiments}

The experiments with Azur A showed that during equilibration and standing for 8 weeks, less than $1 \%$ of the polyelectrolyte could be detected in the supernatant ( $[\text { PLE-A }]_{0}=5 \mathrm{~g} / 100 \mathrm{ml}$, dose $\left.15 \mathrm{Mrads}\right)$. When $10 \mathrm{~g}$ of a swollen gel, $[P L E-A]_{0}=10 \mathrm{~g} / 100 \mathrm{ml}$, dose $15 \mathrm{Mrads}$, equilibrium water content $93.9 \%$, were brought into contact with $1 \mathrm{ml}$ of $0.16 \mathrm{M} \mathrm{NaCl}$ solution less than $5 \cdot 10^{-3} \mathrm{mg}$ of polyelectrolyte was present in the sodium chloride solution after standing for $1 \mathrm{~h}$ at $37^{\circ} \mathrm{C}$ and $24 \mathrm{~h}$ at $0^{\circ} \mathrm{C}$.

\section{Biological activity}

The kallikrein-generation test, developed by Kluft ${ }^{40,41}$. was used to explore the ability of the gels to activate factor XII. When factor XII becomes activated by a 


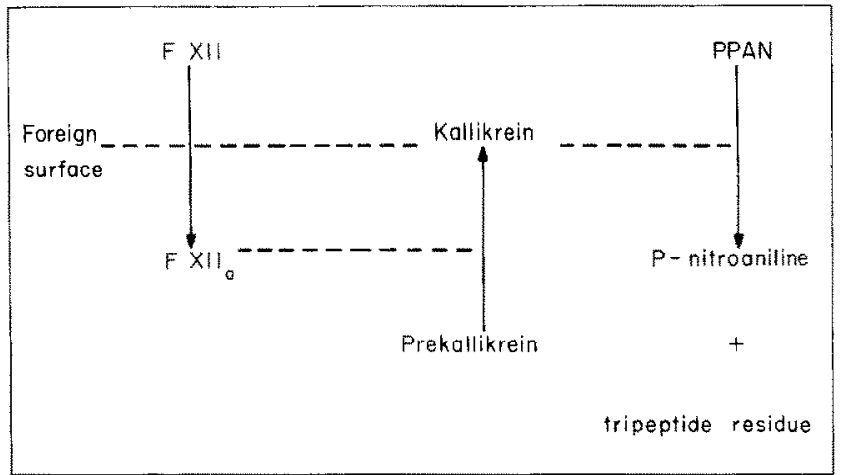

Scheme 1 Representation of the kallikrein-generation test.

hydrogel, subsequently prekallikrein is activated by factor $\mathrm{XII}_{a}$ (see scheme 1), resulting in the formation of kallikrein. The test is carried out at $0^{\circ} \mathrm{C}$ to prevent inactivation of the formed kallikrein by plasma inhibitors.

Activation of factor XII was also studied using the contact promoted shortening of the thrombotest (CPSthrombotest $)^{42}$. When factor XII is activated by a foreign surface, factor VII, from the extrinsic pathway, changes into factor $\mathrm{VII}$. This factor can be activated more rapidly than factor VII itself. Factor VII* is stable at $0^{\circ} \mathrm{C}$. In this way factor $\mathrm{VII} *$ can accumulate without loss of activity at $0^{\circ} \mathrm{C}$. This mechanism has been studied extensively by Gjønnaess $^{42}$. This principle was applied to detect the ability of the hydrogels to activate factor XII, since it was known that the contact promated shortening of the thrombotest is about 20-100 times more sensitive than the kallikrein-generation test (Kluft et al, unpublished results).

When after a certain incubation time, a shortening of the clotting time of the plasma is observed this will be an indication for the formation of factor $\mathrm{VII*}$ which on its turn is an indication for the formation of factor $\mathrm{XII}_{\mathrm{a}}$ (see scheme 2). The adsorption of AT III by the hydrogels was studied by immunochemical assay according to Laurell ${ }^{39}$ in the supernatant after incubation of the gels with citrated blood. The results of the biological activity measurements are shown in Table 3.

The polyelectrolyte hydrogel derived from PLE-A does not deplete AT III from blood. The finding of AT III percentages of more than $100 \%$ is the result of dilution of the blood with the gel, which is not identical to dilution with buffer as control $(100 \%)$. It demonstrates clearly that AT III was apparently not able to penetrate in the matrix of the hydrogels H-PLE-B and H-PLE-C within the incubation time of $1 \mathrm{~h}$.

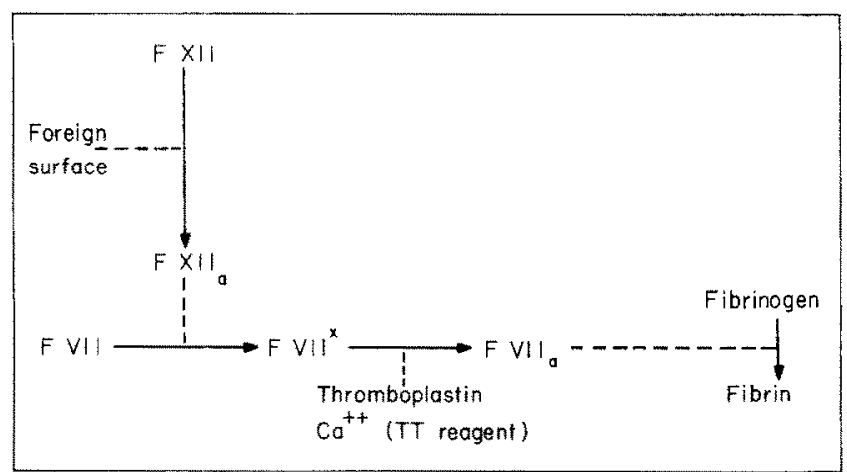

Scheme 2 The principle of the contact promoted shortening of the thrombotest.
Table 3 Antithrombin III adsorption and activation of factor XII by the hydrogels

\begin{tabular}{|c|c|c|c|c|c|}
\hline \multirow{2}{*}{$\begin{array}{l}\text { Hydrogel } \\
1\end{array}$} & \multirow{2}{*}{$\begin{array}{l}\text { equil. } \\
\text { water } \\
\text { cont. } 1 \%) \\
( \pm 0.4 \%)\end{array}$} & \multirow{2}{*}{$\begin{array}{l}\text { AT III } \\
(\%) \\
2\end{array}$} & \multicolumn{2}{|c|}{$\begin{array}{l}\text { kallikrein- } \\
\text { generation } \\
(\%)\end{array}$} & \multirow{2}{*}{$\begin{array}{l}\text { CPS-thrombo- } \\
\text { test }(n=4 \pm \text { sd) } \\
\text { (sec) } \\
5\end{array}$} \\
\hline & & & 3 & 4 & \\
\hline H-PLE-A & 93.9 & 96 & 0.4 & 92 & $16.5 \pm 1.5$ \\
\hline H.PLE-B & 91.0 & 153 & 0.9 & 46 & $20.9 \pm 1.7$ \\
\hline H-PLE-C & 93.2 & 123 & 0.5 & 60 & $17.4 \pm 1.1$ \\
\hline
\end{tabular}

1 solutions of PLE-X of $10 \mathrm{~g} / 100 \mathrm{ml}$ were irradiated with $15 \mathrm{Mrads}$, followed by equilibration with $0.16 \mathrm{M} \mathrm{NaCl}$.

2 residual AT III content of blood after incubation with gels, relative to blank experiment with $0.16 \mathrm{M} \mathrm{NaCl}$ (=100\% AT III).

$3 \%$ of maximal kallikrein generation (gel).

$4 \%$ of maximal kallikrein generation (gel + dextran sulphate). 5 CPS-thrombotest with: dextran sulphate $\quad 14.9 \pm 0.6$

$$
0.16 \mathrm{M} \mathrm{NaCl} \quad 36.9 \pm 4.6
$$

It is interesting to note that the polyelectrolyte PLE-A in aqueous solution acts as an antithrombincofactor, as has been reported previously ${ }^{26}$. It will be investigated in a subsequent study whether the hydrogels sufficiently have retained or whether they have lost this heparin-like action. With the kallikreingeneration test it was found that the gels do not activate factor XII, despite the prolonged activation time used in the test. With the hydrogels H-PLE-B and H-PLE-C the maximal kallikrein activity was not found after the addition of dextran sulphate to the plasma/gel mixture. This means that the hydrogels H-PLE-B and H-PLE-C adsorb factor XII and/or (pre)kallikrein to some extent. With the more sensitive CPS-thrombotest, however, for all hydrogels activation of factor XII could be demonstrated. Using this test it is still possible to measure the effect of $25 \mathrm{ng} / \mathrm{ml}$ dextran sulphate in contrast to the kallikrein-generation test, which has a detection limit of about $0.5 \mu \mathrm{g} / \mathrm{ml}$.

From the results presented in this article it can be concluded that by irradiation of the polyelectrolyte solutions, hydrogels can be prepared with varying water content and mechanical strength.

The strength of the gels is directly related to the equilibrium water content of the hydrogels. Most of the gels are rather weak, but it is possible to improve the mechanical strength considerably by choosing the proper conditions.

Measurements of biological activity using the very sensitive CPS-thrombotest indicated a low potency for activation of factor XII, which could not be observed in a kallikrein-generation test. Added to the fact that the hydrogels do not deplete ATIII from blood, these hydrogels are to be considered promising biomaterials.

\section{ACKNOWLEDGEMENT}

The authors wish to thank Dr. T. Beugeling and Ir. H.G. ten Barge of the Twente University, Prof. Dr. A. Hummel of the Interuniversity Reactor Institute (Delft) and Dr. E.J.P. Brommer of the Gaubius Institute TNO (Leiden) for their stimulating discussions and helpful comments.

\section{REFERENCES}

1 Ratner, B.D. and Hoffman, A.S., Synthetic hydrogels for biomedical applications. in Hydrogels for Medical and Related Applications (Ed. J.D. Andrade) ACS Symposium Series, No 31, Washington, D.C., 1976, p. 1-36.

2 Wichterle, D. and Lim, D., Hydrophilic gels for biological use, Nature, 1960, 185, 117-118

3 Refolo, M.F. and Yasuda. H., Hydrogels from 2-hydroxyethyl methacrylate and propylene glycol monoacrylate, J. Appl. Polym. Sci., 1965, 9, 2425-2435 
4 Janáček, J., Mechanical behaviour of hydroxyalkyl methacrylate polymers and copolymers, J. Macromol. Sci., 1973, 9, 1-47.

5 Bruck, S.D., Aspects of three types of hydrogels for biomedical applications, J. Biomed. Mater. Res., 1973, 7. 387-404.

6 Kearny, J.J. and Amara, I., Mechanically stable non-thrombogenic hydrogels, Polym. Sci. and Techn, vol. 7 (Biomed. Appl. of Polym.), 1975, 75-83.

7 Ikada, $Y$. and Mita, T., Preparation of hydrogels by radiation technique, Rad. Phys. Chrem. 1977, 9, 633-645.

8 Peppas, N.A. and Merrill, E.W., Development of semicrystalline poly(vinyl alcohol) hydrogels for biomedical applications, $J$ Biomed. Mater. Res., 1977, 11, 423-434.

9 Peppas, N.A. and Merrill, E.W., Crosslinked poly(vinyl alcohol) hydrogels as swollen elastic networks, J. Appl. Polym. Sci., 1977, 21, 1763-1770.

10 Peppas, N.A. and Merrill, E.W., Poly(vinyl alcohol) hydrogels: reinforcement of radiation-crosslinked networks by crystallization, J. Polym. Sci., Polym. Chem. Edn., 1976, 14, 441-457.

11 Peppas, N.A., Characterization of homogeneous and pseudo composite homopolymers and copolymers for articular cartilage replacement, Biomat., Med. Dev., Art. Org., 1979, 7(3), 421-433.

12 Holly, F.J. and Refojo, M.F., Water wettability of hydrogels, in Hydrogels for Medical and Related Application (Ed. J. D. Andrade) ACS Symposium Series, No 31, Washington, D.C., 1976, p. 252 266.

13 Muzykewicz, K.J., Crowell, E.B., Jr, Hart, A.P., Schults, M., Hill, C.G., Jr and Cooper, S.L., Platelet adhesion and contact activation time test on HEMA coated cellulose acetate membranes, $J$ Biomed. Mater. Res., 1975, 9, 487-499.

14 Brash, J.L., Hydrophobic polymer surfaccs and their interactions with blood, Ann. N.Y. Acad. Sci., 1977, 283, 356-371

15 Ratner, B.D., Hoffman, A.S., Hanson, S.R., Harker, L.A. and Whiffen, J.D., Blood-compatibility-water-content relationships for radiation-grafted hydrogels, J. Polym. Sci., Polym. Symp., 1979, 66, 363-375

16 Ratner, B.D., Hoffman, A.S. and Whiffen, J.D., Blood compatibility of radiation-grafted hydrogels, Biomat. Med. Dev. Artif. Organs, 1975, 3, (1), 115-120.

17 Gott, V.L. and Baier, R.E., Evaluation of materials by vena cava rings in dogs, vol 1, National Heart and Lung Institute Annual Report PH 43-68-84-3-1, National Institute of Health, Bethesda, Maryland, 1972.

18 Daniels, A.U. and Mortensen, J.D., In vivo testing of polymers for thrombogenicity, Biomat. Med. Dev. Artif. Org, 1974, 2, 365-377.

19 Kusserow, B.K., Larrow, R.W. and Nichols, J.E., Analysis and measurement of the effect of materials on blood leucocytes, erythrocytes and platelets, National Heart and Lung Institute Annual Report PH 43-68-1472-2, National Institute of Health, Bethesda, Maryland, 1974

20 Charlesby, A., Use of high energy radiation for crosslinking and degradation, Rad. Phys. Chem., 1977, 9, 17-29.

21 Hoffman A.S. Applications of radiation processing in biomedica engineering - A review of the preparation and properties of novel biomaterials, Rad. Phys. Chem., 1977, 9, 207-219.

22 Alexander, $P$. and Charlesby, A., Effect of X-rays on synthetic polymers in aqueous solution, J. Polym. Sci., 1957, 23, 355-375.

23 Silverman, J., Basic concepts of radiation processing, Rad. Phys. Chem. 1977, 9, 1-15.

24 Den Heyer, J., Shadid, O.B., Cornelisse, J. and Havinga, E., Photoreactions of aromatic compounds XXXV. Tetrahedron, 1977, 33 779-786.

25 Van der Does, L. Hofman, J. and Van Utteren, T.E.C., Reaction of $\mathrm{N}$-chlorosulfonyl isocyanate with unsaturated polymers. Route to a synthesis of polyampholytes, J. Polym. Sci., Polym. Lett. Ed. $1973,11,169-172$.

26 Beugeling, T., Van der Does, L., Bantjes, A. and Sederel, W.L.
Antithrombin activity of a polyelectrolyte synthesized from cis 1,4-polyisoprene, J. Biomed Mater. Res., 1974, 8, 375-379.

27 Beugeling, T., Van der Does, L., Rejda, B.V. and Bantjes, A Antithrombogenic polymers synthesized from polyisoprenes, in: Biocompatibility of Implant Materials, (Ed. D. Williams) Sector, London, 1976, p 187-192.

28 Van der Does, L., Beugeling, T., Froehling, P.E. and Bantjes, A. Synthetic polymers with anticoagulant activity, J. Polym. Sci. Polym. Symp., 1979, 66, 337-348.

29 Van der Does L., Van Duijl, J.F., Sederel, L.C. and Bantjes, A. Modified polymers from cis-1,4-polyisoprene, J. Polym. Sci., Polym. Lett. Ed., 1980, 18, 53-58.

30 Sederel, L.C., Van der Does, L., Beugeling, T., Van Duijl, J.F. and Bantjes, A., Anticoagulant activity of polyelectrolytes and their behaviour in surface coatings, Proc. Third Intemationdl Conference on Plastics in Medicine and Surgery of the Plastic and Rubber Institute, Enschede, The Netherlands, June 21-22, 1979, p 35.1-35.8.

31 Sederel, L.C., Van der Does, L. Van Duijl, J.F., Beugeling, T. and Bantjes, A., Anticoagulant activity of a synthetic heparinoid in relation to molecular weight and $\mathrm{N}$-sulfate content, J. Biomed. Mater. Res. 1981, 15, 819-827.

32 Froehling, P.E., Thesis, 1977, Antithrombogenic Surface Coatings Based on a Synthetic Heparinoid Polyelectrolyte, Twente University of Technology, Enschede, The Netherlands.

33 Froehling, P.E., Kolar, Z. and Bantjes, A., Adsorption of a synthetic heparinoid polyelectrolyte on an ion-exchange surface, $J$. Coll. Interf. Sci., 1977, 62, 35-39.

34 Beugeling, T., Feijen, J., Tijhuis, A.H.J., Froehling, P.E., De Jongh, M.A., Looze-van Iperen, M. and Bantjes, A., Reduced platele adhesion onto polymer surfaces coated with a synthetic heparinoid polyelectrolyte. Investigations on blood-surface interactions with the aid of a flow system, Proc. Eur. Soc. Artif. Organs, 1976 3, 76-82.

35 Leininger, R.I., Crowley, J.P., Falb, R.D. and Grode, G.A., Three years experience in vivo and in vitro with surfaces and devices treated by the heparin-complex method, Trans. Amer. Soc. Artif. Int. Organs, 1972, 18, 312-315.

36 Scdorel, L.C., Olijslager, J., De Koning, H.W.M., Van Der Does, L., Beugeling, T., Feijen, J., Bantjes, A. and Caamuleau, R.A.F.M Non-thrombogenic surfaces by radiation induced grafting and crosslinking of a synthetic polyelectrolyte: preparation and in vitro studies, Comac Workshop on: New Aspects in Anticoagulan Therapy During Extracorporeal Circulation, Lyndhurst (UK), December 1979.

37 De Koning, H.W.M., Chamuleau, R.A.F.M., Sederel, L.C., and Bantjes, A coating and blood compatibility of amberlite XAD-4, Proc. International Symposium on Artificial Liver Support, Celle (Germany), June 1980.

38 Jaques, L.B. and Wollin, A., A modified method for the colorimetric determination of heparin, Can. J. Physial. Pharmac. $1967,45,787-794$.

39 Laurell, C.B.: Quantitative estimation of proteins by electrophoresis in agarose gel containing antibodies, Anal. Biochem, 1966, 15, 45-52

40 Kluft, C., Determination of prekallikrein in human plasma: optimal conditions for activating prekallikrein. J. Lab. Clin. Med., 1978, 91. 83-95.

41 Kluft, C., Trumpi-Kalshoven, M.M. and Jie, A.F.H., Crucial conditions for the determination of prekallikrein levels in plasma with chromogenic substrates. In: Chromogenic Peptide Substrates: Chemistry and Clinical usage. (Ed M.F. Scully and V.V. Kakkar) Churchill Livingstone, 1979, p 84-92.

42 Gjønnaess, H., Cold promoted activation of factor VII. III: Relation to the kallikrein system, Thromb. Diath. Haemorrh., 1972, 28, 182-193. 